\title{
Peptide Immunotherapy in Experimental Autoimmune Encephalomyelitis
}

\author{
Stephen M. Anderton
}

\begin{abstract}
We now have potent drugs available to treat the inflammatory component of multiple sclerosis (MS). However, not all patients respond, the drugs are not curative, and the associated risks to beneficial immune surveillance are considerable. A more desirable approach is to specifically target those comparatively rare $\mathrm{T}$ lymphocytes that are orchestrating the autoimmune attack. Using the autoantigen itself to instill immune tolerance in those cells remains a holy grail of immunotherapy. Peptide immunotherapy (PIT) is highly effective at silencing autoimmune responses in experimental autoimmune encephalomyelitis (EAE), and clinical trials of PIT are underway in MS. This review discusses the current paradigms for PIT-induced tolerance in naïve T cells. It highlights
\end{abstract} the need for better understanding of the mode of action of PIT upon

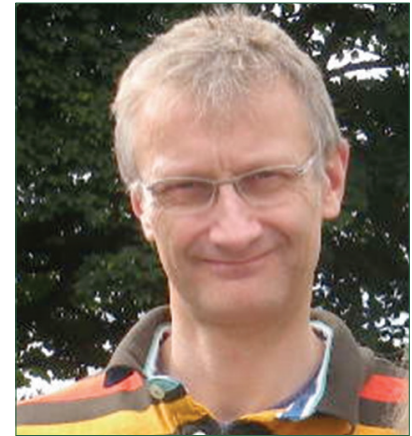

Prof. Stephen M. Anderton memory and effector T cells that are responsible for driving/sustaining ongoing autoimmune pathology. Recent studies in EAEsuggest genetic and epigenetic changes in these pathogenic T-cell populations in response to PIT. Finally, future challenges to effective translation of PIT to the clinic are considered. (Biomed J 2015;38:206-214)

\section{Key words: experimental autoimmune encephalomyelitis, multiple sclerosis, peptide immunotherapy, $\mathbf{T}$ cells, tolerance}

\section{The benefits of antigen-based immunotherapy}

Ctudies on the immunopathogenesis of experimental autoimmune encephalomyelitis (EAE) have provided a series of immunomodulatory approaches that have translated to the treatment of the inflammatory component of multiple sclerosis (MS) ${ }^{[1]}$ More generally, there has been a significant expansion in the immunomodulatory options for the treatment of human autoimmune disease. These include biologics as well as small molecule inhibitors. ${ }^{[2-4]}$ However, an inescapable concern over the use of such therapeutic options is that they will impact adversely upon beneficial immunity as well as the unwanted function of those relatively rare populations of lymphocytes that are driving pathology. This is well exemplified by the risks associated with the use of natalizumab/Tysabri in MS. This monoclonal antibody, which targets $\alpha 4$ integrin to inhibit T cell entry into the CNS, can be remarkably effective in relapsing remitting MS (RRMS). However, the concomitant interruption of normal immunosurveillance of the tissues can, in some patients, lead to viral reactivation and development of progressive multifocal leukoencephalopathy ${ }^{[5]}$ Whilst clinical stratification can mitigate this risk, ${ }^{[6]}$ it highlights the challenge posed by the use of potent drugs that affect the immune system globally. Other current MS drugs come with the same challenge.

Lymphocytes are defined by their expression of antigen-responsive receptors. An approach that can specifically target pathogenic lymphocytes by stimulating them through their antigen receptors, i.e., antigen-based immunotherapy, should avoid compromising beneficial immune function. The induction of T-cell tolerance using antigen-based strategies is, therefore, often referred to as the holy grail for immunotherapy of autoimmune and allergic diseases. ${ }^{[7]}$ Indeed, "specific immunotherapy" based on the administration of allergen extracts, or individual allergen proteins,

From the MRC Centre for Inflammation Research, Centre for Multiple Sclerosis Research and Centre for Immunity Infection and Evolution, University of Edinburgh, Edinburgh, UK

Received: Jan. 5, 2015; Accepted: Apr. 24, 2015

Correspondence to: Prof. Stephen M. Anderton, Centre for Inflammation Research, University of Edinburgh. 47 Little France, Crescent Edinburgh, EH16 4TJ, UK. Tel: 44-131-6501000. Fax: 44-131-2426682 E-mail: steve.anderton@

ed.ac.uk

DOI: $10.4103 / 2319-4170.158510$ 
is a long-established option for the desensitization of allergic patients. ${ }^{[8,9]}$ Despite robust preclinical data obtained in rodent models, clinical trials aimed at establishing oral tolerance to autoantigens in rheumatoid arthritis and MS were unsuccessful. ${ }^{[10]}$ However, interest in antigen-induced tolerance remains strong, particularly around the use of synthetic peptides containing defined epitopes recognized by autoreactive $\mathrm{T}$ cells. ${ }^{[1]}$ This review will consider the options for peptide immunotherapy (PIT), what we have learned from studies in EAE, and the challenges that remain for successful clinical translation.

\section{EAE as a testing ground for PIT}

Whilst EAE is not MS, it serves as the best model for the inflammatory component of MS and is the prototypic $\mathrm{CD} 4^{+} \mathrm{T}$-cell-mediated autoimmune disease. ${ }^{[1,12]} \mathrm{A}$ series of T-cell epitopes are well-defined for a range of CNS myelin autoantigens: ${ }^{[13]}$ most notably, myelin basic protein (MBP), proteolipid protein (PLP), and myelin oligodendrocyte glycoprotein (MOG), but there are others. Therefore, EAE is an ideal model system in which the efficacy of PIT can be tested and its mechanistic basis can be probed. PIT has been shown to be highly effective in preventing the development of EAE in many studies. ${ }^{[14-16]}$ Fewer studies have tested the ability of PIT to reverse ongoing EAE, which is of course more analogous to the clinical imperative. However, new mechanistic studies are now starting to examine how PIT can influence effector and memory T cells in EAE and other T-cell-driven immunopathologies.

The paradigm that immunization with a myelin peptide in complete Freund's adjuvant (CFA) leads to EAE, whereas initial administration of the same peptide without adjuvant, in soluble form in saline, prevents EAE following subsequent immunization has been established for over 20 years. ${ }^{[17]}$ Early studies assessed changes to myelin-reactive T-cell function at the primed lymph node level, i.e., were autoantigen-induced proliferation and cytokine production altered in recall assays? The availability of mouse lines bearing transgenic T-cell receptors (TCRs) that recognize individual myelin peptides has increased the level of sophistication that can be achieved in understanding the mode of action of PIT. ${ }^{[1,18-22]}$ Although some myelin peptide-major histocompatibility complex (MHC) tetramers are available to analyze endogenously generated responses amongst polyclonal TCR repertoires, ${ }^{[23-25]}$ these have not been adopted broadly for these types of studies.

\section{Mechanisms of PIT}

Studies in non-transgenic systems suggested that a 4-day window is required after PIT for T cell unresponsiveness to develop. ${ }^{[14]}$ What happens in this 4-day period? Naïve T cells receive an antigenic signal through their TCR when exposed to PIT, but do not receive the necessary co-stimulation that is provided by the antigen presenting cell (APC) exposed to inflammatory signals such as those provided with CFA. ${ }^{[26]}$ This is exemplified by the fact that if the soluble adjuvant lipopolysaccharide (LPS) is included in the PIT inoculum, tolerance is prevented. ${ }^{[26,27]}$ Broadly, peripheral T-cell tolerance can be categorized as having three mechanisms: (1) apoptotic T-cell death; (2) T-cell survival, but in an unresponsive state (often called anergy); and (3) differentiation toward suppressive/regulatory T-cell function. For the latter mechanism, regulatory function might be instilled through expression of Foxp3, the master regulator of T regulatory (Treg) cell differentiation and function, ${ }^{[28]}$ or through non-Foxp3-dependent mechanisms such as strong IL-10 production. ${ }^{[11]}$ Of note, IL-10 production can also be a key component of Foxp3+ Treg cell activity, although there is a range of suppressive functions that these essential cells have at their disposal. ${ }^{[29]}$ Which of these three pillars of immune tolerance dominates following exposure to PIT remains a matter of debate and might well vary for different experimental protocols and for T cells in different states of activation and differentiation. ${ }^{[30]}$

Some effects of PIT are clear, however. Firstly, tolerance induction is not a null event; it is an active process that is dependent on TCR signaling following ligation of the peptide-MHC complex. In fact, it is difficult to discern any early differences in the behavior of $\mathrm{T}$ cells exposed to PIT versus PIT + LPS. ${ }^{[26]}$ The T cells clearly are activated. Carboxyfluorescein succinimidyl ester-loaded TCR transgenic T-cell transfer experiments show minimal differences in the rates of proliferation between PIT-exposed and PIT + LPS-exposed T cells. However, by the key 4-day time-point, whilst PIT + LPS-exposed T cells continue to accumulate, those exposed to PIT alone become increasingly scarce. ${ }^{[26]}$ This suggests that activation of naïve T cells commences in response to PIT, but this is abortive, leading to their apoptosis. Lymph node imaging studies using oral administration of whole antigen in tolerogenic form (alone) versus immunogenic form (together with cholera toxin as adjuvant) suggested that the T cell-APC clusters that formed during tolerance were shorter-lived than those formed during immunization. ${ }^{[31]}$ Whilst this would be consistent with less-stable T-cell expansion in response to tolerogenic stimulation, differences between oral tolerance and PIT need to be considered when extrapolating between the two approaches.

The molecular basis for abortive T-cell activation in response to PIT is understood to some extent. Co-administration of agonistic antibodies binding the co-stimulatory molecules CD 40 or OX 40 at the time of PIT can prevent the induction of tolerance (substituting for the use of LPS)..$^{32,33]}$ This correlates with sustained T-cell numbers by driving the expression of anti-apoptotic molecules Bcl-2 and survivin in the responding $\mathrm{T}$ cells. These are dependent on OX 40 
signaling, ${ }^{[34,35]}$ which is mediated either directly by the anti-OX40 or indirectly by elevated OX40 ligand expression on the peptide-MHC-presenting APC, triggered by CD40 signaling driven by the anti-CD40. CD40 ligation also boosts the expression of CD80 and CD86 by APC, ${ }^{[36]}$ as does LPS exposure. ${ }^{[26]}$ This suggests that inadequate $\mathrm{CD} 28$ signaling to the $\mathrm{T}$ cells is also a component of PIT-induced tolerance. However, it is unlikely that CD28 signaling is totally absent, given the steady-state expression of CD80 and CD86 by APC, particularly by dendritic cells (DC). Also, we have observed that administration of peptide-loaded CD40-/- DC can induce an abortive T-cell response that looks very similar to that seen following PIT. Importantly, these "tolerogenic" CD40-/- DC had been activated with LPS and consequently had elevated CD80 and CD86 expression, ${ }^{[37]}$ further calling into question the necessity for inadequate CD28 signaling to impose T-cell tolerance. Of note, some current clinical trials of "tolerogenic" DC also incorporate LPS exposure as a means of enhancing their capacity for antigen presentation ${ }^{[38]}$ It is also worth noting here that whilst co-administration of PIT with either LPS, anti-CD40, or anti-OX40 can subvert the cellular processes that normally lead to tolerance, these "adjuvants" cannot by themselves drive T-cell activation sufficiently to the point that EAE ensues. Subsequent immunization with peptide in CFA is still required for this. ${ }^{[32]}$

The above studies argue for apoptotic death as a major component to naïve T-cell tolerance following PIT. However, this cannot be the entire story. Anti-CD40 and anti-OX40 have also been reported to overcome established tolerance. ${ }^{[33]}$ If so, a small but sufficient population of antigen-responsive $T$ cells must survive to be reactivated. Nevertheless, these cells are unresponsive to immunization with peptide + CFA. Are these cells anergic? Clonal anergy was initially described as an unresponsive state induced in cultured T-cell lines stimulated through their TCRs in the absence of (CD28) co-stimulation. ${ }^{[39]}$ These cells were then unable to produce IL-2 upon full restimulation, but could upregulate the high-affinity IL-2 receptor, CD25. IL-2 receptor signaling is a key component of T-cell immunity, promoting T-cell proliferation and survival. Anergic T cells, lacking autocrine IL-2 production, therefore show impaired clonal expansion upon TCR stimulation, which can be restored with exogenous IL-2. Notably, such classically anergic T cells do retain the capacity to produce effector cytokines such as interferon (IFN)- $\gamma$ and IL-4. ${ }^{[39]}$ Early studies suggested that lymph node cells retrieved after immunization of mice that previously received PIT had a global impairment in their ability produce IL-2 and effector cytokines upon rechallenge with myelin peptides. ${ }^{[14,15,17]}$ This suggests an unresponsiveness that is subtly different to classical anergy, but there are caveats. Firstly, the numbers of myelin-responsive T cells in those primed lymph node populations were uncertain.
Second, an important time-point to assess the responsiveness of PIT-treated T cells would be when they are challenged in vivo by immunization. This is most easily addressed using TCR transgenic T cells to elevate their frequency. Such studies showed that $\mathrm{T}$ cells retrieved from the spleens of mice 7 days after a single dose of PIT failed to produce IL-2 or IFN- $\gamma$ upon in vitro re-challenge with peptide. ${ }^{[0]}$ This time-point would routinely be the day of immunization for EAE induction, and these data, therefore, indicated that the unresponsive state is established by this time (i.e., second exposure to antigen is not required to drive the unresponsive features seen in the earlier primed lymph node studies).

\section{PIT-induced regulatory function}

From the above studies, it seems that naïve $\mathrm{T}$ cells enter an abortive phase of clonal expansion in response to PIT. Many cells are then deleted through apoptosis and those $\mathrm{T}$ cells that do survive are unresponsive, lacking the ability to produce IL-2 or effector cytokines. These cells cannot, therefore, undergo clonal expansion upon immunization with myelin peptide, and therefore, EAE cannot develop. Two pillars of immune tolerance (death and unresponsiveness) are, therefore, certainly involved in PIT-induced protection from EAE. Is there scope for the third pillar, regulation? It is notable that very few PIT studies have reported robust gains of Foxp3 expression among peptide-responsive T cells. However, it seems that regulation can be induced. In strains of mice in which EAE can be induced using several individual T-cell epitopes, we used PIT to tolerize against a single PLP peptide. This could limit disease initiated not only by subsequent immunization with that same PLP peptide, but also if the mice were immunized with either of two distinct MBP peptides (without inclusion of the PLP peptide in the immunizing inoculum). ${ }^{[15]}$ This was evidence for "bystander suppression" and suggested that PIT had induced a regulatory function among PLP-responsive T cells which could then function within the CNS to dampen disease driven by MBP-responsive T cells (presumably because of presentation of the PLP peptide as a result of myelin damage). However, no solid proof that PLP-responsive $\mathrm{T}$ cells had gained a defined suppressive function was provided by that study. A series of subsequent studies from the Wraith group provided evidence for such mechanism through the induction of IL-10 production. ${ }^{[16,41-43]}$ Using a TCR transgenic line recognizing MBP, those studies showed that this function emerges in response to repeated PIT administration. Notably, at the population level, T cells isolated from mice that have received one to three doses of PIT are able to produce proinflammatory cytokines; but as the number of dose increases, this ability is lost and IL-10 production is favored. The earlier study using PLP peptide used three doses of PIT into non-transgenic mice. The 
model of death/unresponsiveness described above arises from studies which used single doses of PIT which, whilst being sufficient to deliver profound tolerance, might not be sufficient to induce regulatory function. The IL-10 production seen in the Wraith studies did not correlate with gain of Foxp3 expression. ${ }^{[4]}$ Other studies involved prolonged exposure to peptides using implanted osmotic mini-pumps and in this scenario, Foxp3 expression in the corresponding T-cell populations was seen. ${ }^{[45]}$ Together, these studies suggest that sustained/repeated exposure to tolerogenic peptide may be a key requirement for instilling regulatory function, which, variably, can reflect Foxp3+ Treg generation or IL-10 production. The variables that determine the form of regulatory function are unclear. Also, it should be noted here that the above studies used naïve $\mathrm{T}$ cells as a starting point for induction of regulatory function.

The reason a protocol that can drive regulatory function is so appealing and straightforward; not only would such T cells not be dangerous in themselves after PIT, they would also suppress the deleterious effects of other $\mathrm{T}$ cells and, if their persistence could be ensured, they would provide long-lasting "cover" against any proinflammatory $\mathrm{T}$ cells that might arise in the future. Bystander suppression is particularly appealing given that, although several autoantigenic epitopes are characterized in MS, ${ }^{[46-50]}$ we do not know which (if any) of these are the key targets recognized by $\mathrm{T}$ cells driving disease. Therefore, a suppressive T-cell population recognizing a defined myelin epitope could suppress a proinflammatory population recognizing other (perhaps unknown) myelin epitopes, if their localization was sufficiently close. This could be a necessary feature, based on studies using chronic and relapsing EAE models that have described the spreading of T-cell reactivity to additional epitopes over time. ${ }^{[51,52]}$ However, the true extent and importance of epitope spreading remains controversial, ${ }^{[53,54]}$ and a recent study indicated that, even once relapsing disease was established, targeting the $\mathrm{T}$ cells recognizing the inducing epitope was sufficient to limit those relapses. ${ }^{[55]}$

In theory, an induced suppressive T-cell population need not necessarily recognize a defined myelin autoantigen. If the suppressive cells can recognize an autoantigen that is upregulated during inflammation, then these cells might have disease-resolving qualities, regardless of the antigen reactivity of the inciting pathogenic $\mathrm{T}$ cells. Heat shock proteins (HSPs) are candidate antigens to serve as molecular "flags" for attracting suppressive T cells to inflamed tissues. ${ }^{[56]}$ Nasal application of peptides from HSP60 or HSP70 was able to promote Foxp3+ T cells with suppressive function in arthritis models in rat ${ }^{[57]}$ and mouse, ${ }^{[58]}$ respectively. Similarly, nasal application of a peptide from rat HSP60 was able to modulate MBP-driven EAE in rats. ${ }^{[59]}$ The reduction in disease with the HSP60 peptide (using a post-immuni- zation protocol) was equivalent to that seen when the MBP peptide itself was used as the tolerizing antigen.

\section{What type of regulators should we induce?}

Foxp3+ Treg cells seem very adept at suppressing EAE, if given prophylactically. ${ }^{[60]}$ A key point, however, is that these cells are most effective if they recognize myelin autoantigens (polyclonal Treg cells are ineffectual in comparison). ${ }^{[61]}$ Therefore, there is clearly scope for antigen-driven expansion of Foxp3 + cells. The clinical imperative is to reverse ongoing pathology. The scenario above in which regulatory cells need to come into close contact with pre-activated pathogenic cells might best be achieved if the regulatory cells can access and function in the inflamed CNS itself. An impressive accumulation of Foxp3+ Treg cells within the CNS occurs naturally during EAE and we have described that this is essential for spontaneous resolution of the disease. ${ }^{[62]}$ Clearly Treg cells have an ability to infiltrate the inflamed CNS and then rapidly proliferate therein. ${ }^{[63]}$ These cells also have strong suppressive activity. ${ }^{[62,63]}$ We first identified these cells by screening for IL-10 producing cells within the $\mathrm{CNS}^{[62]}$ (although it should be noted that we have since shown that CD4+Foxp3- cells from the CNS can also produce IL-10 following TCR stimulation). ${ }^{[64]}$ Therapeutic studies have shown that Foxp3+ Treg can also limit relapses in EAE and that MBP-responsive Treg can limit PLP-driven disease, analogous to the bystander suppression phenomenon seen with PIT. ${ }^{[61]}$ However, those Treg studies did not identify precisely where the Treg cells were functioning. More work is required to fully understand how best to encourage therapeutically administered Treg to target the CNS. However, as discussed above, the greater challenge is to develop a robust PIT protocol either to expand existing myelin-responsive Treg or to induce de novo Foxp3 expression. It is notable that there is no body of evidence to suggest that pre-existing T effector (Teff) cells can be driven to become Foxp3+ Treg.

A better means of using PIT to generate a dominant suppressive function in Teff cells might be to push them toward IL-10 production, with concomitant loss of proinflammatory cytokine production. ${ }^{[11]}$ This has been achieved by repeated exposure of naïve T cells to PIT $^{[16,41]}$ and there is some evidence to suggest that it might also be achieved in mice that are already immune. ${ }^{[65]}$ Moreover, clinical data from studies using allergen peptides suggest that this might also be achieved in humans. ${ }^{[66]}$ Based on this, IL-10 production has become a key putative "biomarker" to suggest successful induction of immune tolerance/regulation in human studies. However, as with Foxp3 induction, more work is needed to identify a robust and consistent means of achieving this in response to PIT. 


\section{Anaphylaxis as a confounding issue?}

The majority of PIT studies in EAE have focused on the tolerogenic administration of peptide before induction of disease (i.e., targeting $\mathrm{T}$ cells while they are in their naïve state). Of course, this is not the clinical imperative; ongoing disease is driven by effector and memory $\mathrm{T}$ cells. True therapeutic use of PIT in EAE has been hampered due to anaphylactic reactions to soluble peptide in mice that have previously been immunized with the same peptide in CFA, which can trigger production of anti-peptide IgE and IgG1. ${ }^{[67,68]}$ Although the etiopathology of MS is unknown, we can be certain that it is not due to immunization with myelin peptide in CFA. However, hypersensitivity reactions associated with anti-peptide $\operatorname{IgG} 1$ and $\mathrm{IgE}$ following repeated peptide administration led to the cessation of an MS clinical trial. ${ }^{[69]}$ Interestingly, PIT can reverse EAE induced by immunization with intact myelin antigen in CFA, which does not trigger the generation of anti-peptide antibodies (unpublished). Moreover, to seek further proof of principle that PIT could work therapeutically in EAE, we designed an altered peptide ligand (APL) that retained function as a TCR ligand but did not bind antibodies. A single amino acid substitution in the MOG(35-55) peptide was sufficient to produce such an APL. ${ }^{[70]}$ As expected, using this peptide avoided anaphylaxis. Importantly, the APL was capable of reversing EAE induced with the wild-type peptide. In a complementary approach, others have taken a protozoan peptide which has sequence similarity to PLP (139-151) and can stimulate PLP-responsive T cells, but does not bind to anti-PLP (139-151) antibodies. Repeated treatment with this mimic peptide, post-PLP (139-151) immunization, could prevent EAE ${ }^{[55]}$ An additional feature of this study was that the mimic peptide was produced as a non-linear octamer, rather than in monomeric form.

EAE can also be induced by passive transfer of myelin-responsive T cells into non-immunized host mice. ${ }^{[13]} \mathrm{In}$ this case, the hosts do not harbor any anti-peptide antibodies, allowing assessment of the effects of PIT upon pre-formed encephalitogenic Teff cells (discussed below). Despite these data indicating that PIT is able to induce unresponsiveness, even among encephalitogenic effector and memory $T$ cells, the potential development of anti-peptide antibodies through prolonged application of PIT (as exemplified in an MS trial) ${ }^{[69]}$ remains a key consideration facing effective clinical translation.

\section{Transcriptional and epigenetic changes in PIT-responsive T cells}

PIT therefore seems capable of potently modulating the encephalitogenic function of both naïve and pre-activated myelin-responsive $\mathrm{T}$ cells. As described above, this can be variously attributed to apoptotic cell death, functional unresponsiveness or gain of dominant IL-10-producing capacity. In the latter two scenarios, the PIT-responsive $\mathrm{T}$ cells clearly survive, providing opportunities to probe genetic and epigenetic changes that might control the alteration in their function. Indeed, if antigen-responsive $\mathrm{T}$ cells survive following PIT in patients, the stability of tolerance is of paramount importance and it will be crucial to understand these molecular changes and whether they are reversible. The nature of unresponsiveness might be relevant to this question. Classical clonal anergy does not need continued exposure to antigen to be maintained, but can be overcome if exogenous IL-2 is provided, perhaps by $\mathrm{T}$ cells in the proximity responding to foreign antigen during infection. ${ }^{[39]}$ Another form of unresponsiveness, which has been termed adaptive tolerance and might be more analogous to that induced by PIT, does require sustained exposure to antigen to be maintained. ${ }^{[39]}$ It is not clear whether exposure to "physiological" levels of endogenous autoantigen would be sufficient to maintain this unresponsiveness.

The 4-day window required for tolerance to be induced following PIT provides ample opportunity for changes in gene expression to have a role. Use of TCR transgenic models is now allowing this possibility to be studied. The $\mathrm{Tg} 4$ mouse expresses a transgenic TCR recognizing the Ac1-9 peptide of MBP ${ }^{[18]}$ As discussed above, repeated administration of PIT is required to induce unresponsiveness in intact $\mathrm{Tg} 4$ mice and this is associated with transient production of proinflammatory cytokines in response to initial doses of PIT, which then wanes, to be replaced by IL-10 production ${ }^{[41]}$ A recent study using subcutaneous delivery of PIT has shown that the initial proinflammatory response can reach clinical relevance via this route, with signs of "cytokine storm." To circumvent this, a dose-escalation regimen was developed. Time-course sampling and Affymetrix GeneChip analysis not only confirmed the gain in IL-10 expression, but also demonstrated dynamic changes in the expression of a range of cell surface molecules, transcription factors and genes involved in cell cycle activity. ${ }^{[71]}$ The transcription factors Maf and Nfil3 were strongly elevated by dose-escalation PIT and these are positively associated with IL-10 production. ${ }^{[72-74]}$ IL-21 production was also elevated in PIT-exposed T cells, which is again consistent with induction of IL-10. ${ }^{[72]}$ Two surface molecules (lymphocyte activation gene 3 [LAG-3] and CD49b) reported to identify IL-10-producing Tr1 cells were also elevated by PIT. ${ }^{[75]}$ LAG-3 is also associated with T-cell exhaustion, ${ }^{[76,77]}$ as are programmed cell death 1 (PD-1) and T cell immunoglobulin and mucin domain-3 (TIM-3), which were also elevated by PIT. A key advance would be to identify a surrogate surface phenotype that identifies tolerant $\mathrm{T}$ cells (IL-10 producing or otherwise). Of note in this context, no combination of the 
above surface markers could specifically discern IL-10-producing T cells ${ }^{[71]}$ Another important question is how is the inability to produce proinflammatory cytokines driven by PIT in this scenario. Is this dependent on IL-10, or, as seems likely, do other gene changes determine this?

Whilst the gene changes described above are interesting, the experimental setting started with naïve $\mathrm{T}$ cells. We have also investigated how PIT affects $\mathrm{Tg} 4 \mathrm{~T}$ cells, but we used an established passive transfer model in our studies that allows us to focus our attention on a defined cohort of pre-formed pathogenic Teff cells. ${ }^{[13,78]}$ In this scenario, a single intravenous administration of PIT is sufficient to completely silence the pathogenic function of the transferred Teff cells. ${ }^{[79]}$ Transcriptomic (RNA-Seq) analyses of the retrieved tolerized Tg4 Teff cells not only showed gene changes with some similarities, but also marked differences to those described in naïve $\mathrm{Tg} 4 \mathrm{~T}$ cells above (unpublished). A particularly noteworthy difference is that this profoundly unresponsive state induced by PIT is not associated with gain in IL-10 production by Teff cells. However, proinflammatory cytokine production is greatly diminished as is the ability of the tolerized Teff to accumulate within the CNS. This is an important point; PIT is not always dependent on IL-10 production. The gene changes that we see in response to PIT are the subject of ongoing mechanistic investigations. However, in advance of our transcriptomic analyses, we did identify that exposure to PIT markedly elevated the expression of PD-1 by Teff cells. ${ }^{[79]}$ PD- 1 is an important negative regulator of TCR signaling within $\mathrm{T}$ cells ${ }^{[80-82]}$ but it is not a definitive marker for tolerant $\mathrm{T}$ cells, because it is transiently expressed by fully functional T cells following TCR stimulation. ${ }^{[83]}$ However, we found that PIT induced apparently irreversible surface expression of PD-1. Furthermore, PD-1-deficient Tg4 Teff cells could not be silenced by PIT, and thus went on to cause EAE in host mice. ${ }^{[79]}$ Sustained PD-1 expression therefore seems an essential feature of lack of pathogenic activity in PIT-exposed Teff cells and we identified epigenetic changes (cytosine demethylation) associated with stable gene expression within the PD-1 (Pdcd1) promoter that occurred only in Teff cells exposed to PIT. ${ }^{[79]}$ This is of particular interest because similar epigenetic modifications have been noted in the Pdcd1 promoter of virus-specific $\mathrm{CD} 8+\mathrm{T}$ cells that have become functionally exhausted in response to chronic infection. ${ }^{[84]}$

\section{Concluding remarks}

PIT is a very potent means of preventing the development of EAE, and recent studies by us and others indicate that pathogenic activity of myelin-responsive Teff and memory $T$ cells can be profoundly silenced. This has crucial translational consequences. Clinical trials of PIT in MS are underway. A key outstanding issue is how PIT influences the function of Teff cells and T memory cells, since the overwhelming majority of studies aimed at providing mode-of-action data have probed this question using naïve $\mathrm{T}$ cells as the starting population. It seems very likely that naïve $\mathrm{T}$ cells, Teff cells and $\mathrm{T}$ memory cells will respond in different ways to the same PIT protocol. Indeed, we have already reported that this is the case using a model of Th2-driven allergic airways inflammation. ${ }^{[85]}$ Understanding these differences will provide a key advance for clinical translation. There are many questions that still need answers.

Can we reliably induce regulatory function in Teff cells exposed to PIT, and if so is this function stable? Can we drive Foxp3 expression in Teff cells? Do the functional (and genetic/epigenetic) changes induced in Teff cells differ with the PIT protocol deployed (peptide dose, route of administration, timing, etc.)? Importantly, $\mathrm{T}$ cells recognizing autoantigens relevant to MS (or indeed to other autoimmune diseases) will be rare in peripheral blood samples. Can we identify these cells? Flow cytometric approaches using peptide-MHC tetramers, ${ }^{[86,87]}$ or cell surface changes in response to brief in vitro stimulation with antigen ${ }^{[88]}$ suggest that this will become increasingly possible. Can we purify sufficient numbers of autoantigen-responsive cells to allow transcriptional/epigenetic analyses? Again, improved sensitivity assays are likely to make this possible. An alternative "biomarker" for tolerance might be developed if we can define a discrete cell surface phenotype (likely involving the expression of multiple cell membrane-associated molecules) that specifically travels with transcriptional/epigenetic marks of tolerance.

An interesting complication when considering how best to design tolerogenic peptides is the increasing realization that autoreactive $\mathrm{T}$ cells might not recognize the native form of the antigen. Hundreds of possible post-translational modifications to proteins have been described, some with significance to autoimmune T-cell recognition. ${ }^{\left[{ }^{89]}\right.}$ How can we systematically screen patients' T-cell repertoires for responsiveness to these? Clearly, there is considerably more work needed to address these questions, but recent developments in our understanding of EAE, and the cellular and molecular tools available, mean that the model should continue to provide important insights of translational therapeutic value.

\section{Acknowledgment}

Work in the author's laboratory was funded by the UK Medical Research Council, The Wellcome Trust, and the UK Multiple Sclerosis Society. 


\section{REFERENCES}

1. Ben-Nun A, Kaushansky N, Kawakami N, Krishnamoorthy G, Berer K, Liblau R, et al. From classic to spontaneous and humanized models of multiple sclerosis: Impact on understanding pathogenesis and drug development. J Autoimmun 2014;54C:33-50.

2. Ghoreschi K, Gadina M. Jakpot! New small molecules in autoimmune and inflammatory diseases. Exp Dermatol 2014;23:7-11.

3. Miklossy G, Hilliard TS, Turkson J. Therapeutic modulators of STAT signalling for human diseases. Nat Rev Drug Discov 2013;12:611-29.

4. Canete JD, Pablos JL. Biologic therapy in rheumatoid arthritis. Curr Top Med Chem 2013;13:752-9.

5. Schwab N, Schneider-Hohendorf T, Wiendl H. Therapeutic uses of anti-alpha4-integrin (anti-VLA-4) antibodies in multiple sclerosis. Int Immunol 2015;27:47-53.

6. Plavina T, Subramanyam M, Bloomgren G, Richman S, Pace A, Lee S, et al. Anti-JC virus antibody levels in serum or plasma further define risk of natalizumab-associated progressive multifocal leukoencephalopathy. Ann Neurol 2014;76:802-12.

7. Garber K. Immunology: A tolerant approach. Nature 2014;507:418-20.

8. Noon L. Prophylactic innoculation against hay fever. Lancet 1911;177:1572-3.

9. Larche M. Peptide immunotherapy for allergic diseases. Allergy 2007;62:325-31

10. Weiner HL. Oral tolerance: Immune mechanisms and treatment of autoimmune diseases. Immunol Today 1997;18:335-43.

11. Larche M, Wraith DC. Peptide-based therapeutic vaccines for allergic and autoimmune diseases. Nat Med 2005;11:S69-76.

12. McPherson RC, Anderton SM. Adaptive Immune Responses in CNS Autoimmune Disease: Mechanisms and Therapeutic Opportunities. J Neuroimmune Pharmacol 2013;8:774-90.

13. McPherson RC, Cambrook HE, O'Connor RA, Anderton SM. Induction of passive EAE using myelin-reactive CD4+ T cells. Methods Mol Biol 2014;1193:187-98.

14. Liu GY, Wraith DC. Affinity for class II MHC determines the extent to which soluble peptides tolerize autoreactive $\mathrm{T}$ cells in naive and primed adult mice--implications for autoimmunity. Int Immunol 1995;7:1255-63.

15. Anderton SM, Wraith DC. Hierarchy in the ability of T cell epitopes to induce peripheral tolerance to antigens from myelin. Eur J Immunol 1998;28:1251-61.

16. Sundstedt A, O'Neill EJ, Nicolson KS, Wraith DC. Role for IL-10 in suppression mediated by peptide-induced regulatory $\mathrm{T}$ cells in vivo. J Immunol 2003;170:1240-8

17. Metzler B, Wraith DC. Inhibition of experimental autoimmune encephalomyelitis by inhalation but not oral administration of the encephalitogenic peptide: Influence of MHC binding affinity. Int Immunol 1993;5:1159-65.

18. Liu GY, Fairchild PJ, Smith RM, Prowle JR, Kioussis D, Wraith DC. Low avidity recognition of self-antigen by $\mathrm{T}$ cells permits escape from central tolerance. Immunity 1995;3:407-15.

19. Bettelli E, Pagany M, Weiner HL, Linington C, Sobel RA, Kuchroo VK. Myelin oligodendrocyte glycoprotein-specific T cell receptor transgenic mice develop spontaneous autoimmune optic neuritis. J Exp Med 2003;197:1073-81.
20. Goverman J, Woods A, Larson L, Weiner LP, Hood L, Zaller DM. Transgenic mice that express a myelin basic protein-specific $\mathrm{T}$ cell receptor develop spontaneous autoimmunity. Cell 1993;72:551-60.

21. Lafaille JJ, Nagashima K, Katsuki M, Tonegawa S. High incidence of spontaneous autoimmune encephalomyelitis in immunodeficient anti-myelin basic protein $\mathrm{T}$ cell receptor transgenic mice. Cell 1994;78:399-408.

22. Waldner H, Whitters MJ, Sobel RA, Collins M, Kuchroo VK. Fulminant spontaneous autoimmunity of the central nervous system in mice transgenic for the myelin proteolipid protein-specific $\mathrm{T}$ cell receptor. Proc Natl Acad Sci USA 2000;97:3412-7.

23. Radu CG, Anderton SM, Firan M, Wraith DC, Ward ES. Detection of autoreactive $\mathrm{T}$ cells in $\mathrm{H}-2 \mathrm{u}$ mice using peptide-MHC multimers. Int Immunol 2000;12:1553-60.

24. Korn T, Reddy J, Gao W, Bettelli E, Awasthi A, Petersen TR, et al. Myelin-specific regulatory T cells accumulate in the CNS but fail to control autoimmune inflammation. Nat Med 2007;13:423-31.

25. Reddy J, Illes Z, Zhang X, Encinas J, Pyrdol J, Nicholson L, et al. Myelin proteolipid protein-specific $\mathrm{CD} 4+\mathrm{CD} 25+$ regulatory cells mediate genetic resistance to experimental autoimmune encephalomyelitis. Proc Natl Acad Sci USA 2004;101:15434-9.

26. Hochweller K, Anderton SM. Kinetics of costimulatory molecule expression by $\mathrm{T}$ cells and dendritic cells during the induction of tolerance versus immunity in vivo. Eur J Immunol 2005;35:1086-96.

27. Vella AT, McCormack JE, Linsley PS, Kappler JW, Marrack P. Lipopolysaccharide interferes with the induction of peripheral $\mathrm{T}$ cell death. Immunity 1995;2:261-70.

28. Wing K, Sakaguchi S. Regulatory T cells exert checks and balances on self tolerance and autoimmunity. Nat Immunol 2010;11:7-13.

29. Vignali DA. Mechanisms of T (reg) Suppression: Still a Long Way to Go. Front Immunol 2012;3:191.

30. Anderton SM. Peptide-based immunotherapy of autoimmunity: A path of puzzles, paradoxes and possibilities. Immunology 2001;104:367-76.

31. Zinselmeyer BH, Dempster J, Gurney AM, Wokosin D, Miller M, $\mathrm{Ho} \mathrm{H}$, et al. In situ characterization of $\mathrm{CD} 4+\mathrm{T}$ cell behavior in mucosal and systemic lymphoid tissues during the induction of oral priming and tolerance. J Exp Med 2005;201:1815-23.

32. Hochweller K, Sweenie CH, Anderton SM. Circumventing tolerance at the $\mathrm{T}$ cell or the antigen-presenting cell surface: Antibodies that ligate CD40 and OX40 have different effects. Eur J Immunol 2006;36:389-96

33. Bansal-Pakala P, Jember AG, Croft M. Signaling through OX40 (CD134) breaks peripheral T-cell tolerance. Nat Med 2001;7:907-12.

34. Rogers PR, Song J, Gramaglia I, Killeen N, Croft M. OX40 promotes $\mathrm{Bcl}-\mathrm{xL}$ and $\mathrm{Bcl}-2$ expression and is essential for long-term survival of CD4 T cells. Immunity 2001;15:445-55.

35. Song J, So T, Cheng M, Tang X, Croft M. Sustained survivin expression from OX40 costimulatory signals drives $\mathrm{T}$ cell clonal expansion. Immunity 2005;22:621-31.

36. Grewal IS, Flavell RA. CD40 and CD154 in cell-mediated immunity. Annu Rev Immunol 1998;16:111-35.

37. Hochweller K, Anderton SM. Systemic administration of antigen-loaded CD40-deficient dendritic cells mimics soluble antigen administration. Eur J Immunol 2004;34:990-8. 
38. Hilkens CM, Isaacs JD. Tolerogenic dendritic cell therapy for rheumatoid arthritis: Where are we now? Clin Exp Immunol 2013;172:148-57.

39. Schwartz RH. T cell anergy. Ann Rev Immunol 2003;21:305-34.

40. Konkel JE, Frommer F, Leech MD, Yagita H, Waisman A, Anderton SM. PD-1 signalling in CD4(+) T cells restrains their clonal expansion to an immunogenic stimulus, but is not critically required for peptide-induced tolerance. Immunology 2010;130:92-102.

41. Burkhart C, Liu GY, Anderton SM, Metzler B, Wraith DC. Peptide-induced $\mathrm{T}$ cell regulation of experimental autoimmune encephalomyelitis: A role for IL-10. Int Immunol 1999;11:1625-34.

42. Massey EJ, Sundstedt A, Day MJ, Corfield G, Anderton S, Wraith DC. Intranasal peptide-induced peripheral tolerance: The role of IL-10 in regulatory $\mathrm{T}$ cell function within the context of experimental autoimmune encephalomyelitis. Vet Immunol Immunopathol 2002;87:357-72.

43. Gabrysova L, Wraith DC. Antigenic strength controls the generation of antigen-specific IL-10-secreting T regulatory cells. Eur J Immunol 2010;40:1386-95.

44. Vieira PL, Christensen JR, Minaee S, O’Neill EJ, Barrat FJ, Boonstra A, et al. IL-10-secreting regulatory T cells do not express Foxp3 but have comparable regulatory function to naturally occurring CD4+CD25+ regulatory T cells. J Immunol 2004;172:5986-93.

45. Apostolou I, von Boehmer H. In vivo instruction of suppressor commitment in naive T cells. J J Exp Med 2004;199:1401-8.

46. Lutterotti A, Sospedra M, Martin R. Antigen-specific therapies in MS-Current concepts and novel approaches. J Neurol Sci 2008;274:18-22.

47. Lutterotti A, Yousef S, Sputtek A, Sturner KH, Stellmann JP, Breiden $\mathrm{P}$, et al. Antigen-specific tolerance by autologous myelin peptide-coupled cells: A phase 1 trial in multiple sclerosis. Sci Transl Med 2013;5:188ra75.

48. Sospedra M, Martin R. Antigen-specific therapies in multiple sclerosis. Int Rev Immunol 2005;24:393-413.

49. Sospedra M, Martin R. Immunology of multiple sclerosis. Ann Rev Immunol 2005;23:683-747.

50. Mazza G, Ponsford M, Lowrey P, Campbell MJ, Zajicek J, Wraith DC. Diversity and dynamics of the T-cell response to MBP in DR2+ ve individuals. Clin Exp Immunol 2002;128:538-47.

51. McRae BL, Vanderlugt CL, Dal Canto MC, Miller SD. Functional evidence for epitope spreading in the relapsing pathology of experimental autoimmune encephalomyelitis. J Exp Med $1995 ; 182: 75-85$.

52. McMahon EJ, Bailey SL, Castenada CV, Waldner H, Miller SD. Epitope spreading initiates in the CNS in two mouse models of multiple sclerosis. Nat Med 2005;11:335-9.

53. Smith PA, Morris-Downes M, Heijmans N, Pryce G, Arter E, O'Neill JK, et al. Epitope spread is not critical for the relapse and progression of MOG 8-21 induced EAE in Biozzi ABH mice. J Neuroimmunol 2005;164:76-84.

54. Kroenke MA, Segal BM. Th17 and Th1 responses directed against the immunizing epitope, as opposed to secondary epitopes, dominate the autoimmune repertoire during relapses of experimental autoimmune encephalomyelitis. J Neurosci Res 2007;85:1685-93.

55. Wegmann KW, Archie Bouwer HG, Whitham RH, Hinrichs DJ. Eluding anaphylaxis allows peptide-specific prevention of the relapsing stage of experimental autoimmune encephalomyelitis. J Neuroimmunol 2014;274:46-52.

56. van Eden W, van der Zee R, Paul AG, Prakken BJ, Wendling U, Anderton SM, et al. Do heat shock proteins control the balance of T-cell regulation in inflammatory diseases? Immunol Today 1998;19:303-7.

57. Zonneveld-Huijssoon E, Roord ST, de Jager W, Klein M, Albani S, Anderton SM, et al. Bystander suppression of experimental arthritis by nasal administration of a heat shock protein peptide. Ann Rheum Dis 2011;70:2199-206.

58. van Herwijnen MJ, Wieten L, van der Zee R, van Kooten PJ, Wagenaar-Hilbers JP, Hoek A, et al. Regulatory T cells that recognize a ubiquitous stress-inducible self-antigen are long-lived suppressors of autoimmune arthritis. Proc Natl Acad Sci USA 2012;109:14134-9.

59. Billetta R, Ghahramani N, Morrow O, Prakken B, de Jong H, Meschter C, et al. Epitope-specific immune tolerization ameliorates experimental autoimmune encephalomyelitis. Clin Immunol 2012;145:94-101.

60. Anderton SM, Liblau RS. Regulatory T cells in the control of inflammatory demyelinating diseases of the central nervous system. Curr Opin Neurol 2008;21:248-54.

61. Stephens LA, Malpass KH, Anderton SM. Curing CNS autoimmune disease with myelin-reactive Foxp3+ Treg. Eur J Immunol 2009;39:1108-17.

62. McGeachy MJ, Stephens LA, Anderton SM. Natural recovery and protection from autoimmune encephalomyelitis: Contribution of CD4+CD25+ regulatory cells within the central nervous system. J Immunol 2005; 175:3025-32.

63. O'Connor RA, Malpass KH, Anderton SM. The inflamed central nervous system drives the activation and rapid proliferation of Foxp3+ regulatory T cells. J Immunol 2007;179:958-66.

64. O'Connor RA, Floess S, Huehn J, Jones SA, Anderton SM. Foxp3(+) Treg cells in the inflamed CNS are insensitive to IL-6-driven IL-17 production. Eur J Immunol 2012;42:1174-9.

65. Campbell JD, Buckland KF, McMillan SJ, Kearley J, Oldfield WL, Stern LJ, et al. Peptide immunotherapy in allergic asthma generates IL-10-dependent immunological tolerance associated with linked epitope suppression. J Exp Med 2009;206:1535-47.

66. Larche M. Update on the current status of peptide immunotherapy. J Allergy Clin Immunol Pract 2007;119:906-9.

67. Pedotti R, Mitchell D, Wedemeyer J, Karpuj M, Chabas D, Hattab EM, et al. An unexpected version of horror autotoxicus: Anaphylactic shock to a self-peptide. Nat Immunol 2001;2:216-22.

68. Smith CE, Eagar TN, Strominger JL, Miller SD. Differential induction of IgE-mediated anaphylaxis after soluble vs. cell-bound tolerogenic peptide therapy of autoimmune encephalomyelitis. Proc Natl Acad Sci USA 2005;102:9595-600.

69. Kappos L, Comi G, Panitch H, Oger J, Antel J, Conlon P, et al. Induction of a non-encephalitogenic type $2 \mathrm{~T}$ helper-cell autoimmune response in multiple sclerosis after administration of an altered peptide ligand in a placebo-controlled, randomized phase II trial. The Altered Peptide Ligand in Relapsing MS Study Group. Nat Med 2000;6:1176-82.

70. Leech MD, Chung CY, Culshaw A, Anderton SM. Peptide-based immunotherapy of experimental autoimmune encephalomyelitis without anaphylaxis. Eur J Immunol 2007;37:3576-81. 
71. Burton BR, Britton GJ, Fang H, Verhagen J, Smithers B, Sabatos-Peyton CA, et al. Sequential transcriptional changes dictate safe and effective antigen-specific immunotherapy. Nat Commun $2014 ; 5: 4741$.

72. Pot C, Jin H, Awasthi A, Liu SM, Lai CY, Madan R, et al. Cutting edge: IL-27 induces the transcription factor c-Maf, cytokine IL-21, and the costimulatory receptor ICOS that coordinately act together to promote differentiation of IL-10-producing Tr1 cells. J Immunol 2009; 183:797-801.

73. Apetoh L, Quintana FJ, Pot C, Joller N, Xiao S, Kumar D, et al. The aryl hydrocarbon receptor interacts with c-Maf to promote the differentiation of type 1 regulatory T cells induced by IL-27. Nat Immunol 2010;11:854-61.

74. Motomura Y, Kitamura H, Hijikata A, Matsunaga Y, Matsumoto K, Inoue $\mathrm{H}$, et al. The transcription factor E4BP4 regulates the production of IL-10 and IL-13 in CD4+ T cells. Nat Immunol 2011;12:450-9.

75. Gagliani N, Magnani CF, Huber S, Gianolini ME, Pala M, Licona-Limon P, et al. Coexpression of CD49b and LAG-3 identifies human and mouse T regulatory type 1 cells. Nat Med 2013;19:739-46.

76. Wherry EJ. T cell exhaustion. Nat Immunol 2011;12:492-9.

77. Wherry EJ, Ha SJ, Kaech SM, Haining WN, Sarkar S, Kalia V, et al. Molecular signature of CD8+ T cell exhaustion during chronic viral infection. Immunity 2007;27:670-84.

78. O'Connor RA, Prendergast CT, Sabatos CA, Lau CW, Leech MD, Wraith DC, et al. Cutting edge: Th1 cells facilitate the entry of Th17 cells to the central nervous system during experimental autoimmune encephalomyelitis. J Immunol 2008;181:3750-4.

79. McPherson RC, Konkel JE, Prendergast CT, Thomson JP, Ottaviano R, Leech MD, et al. Epigenetic modification of the PD-1 () promoter in effector $\mathrm{CD} 4 \mathrm{~T}$ cells tolerized by peptide immunotherapy. eLife 2014;3:e3416.

80. Nishimura H, Minato N, Nakano T, Honjo T. Immunological studies on PD-1 deficient mice: Implication of PD-1 as a negative regulator for B cell responses. Int Immunol 1998;10:1563-72.

81. Nishimura H, Nose M, Hiai H, Minato N, Honjo T. Development of lupus-like autoimmune diseases by disruption of the PD-1 gene encoding an ITIM motif-carrying immunoreceptor. Immunity 1999;11:141-51.

82. Keir ME, Butte MJ, Freeman GJ, Sharpe AH. PD-1 and its ligands in tolerance and immunity. Ann Rev Immunol 2008;26:677-704.

83. Riley JL. PD-1 signaling in primary $\mathrm{T}$ cells. Immunol Rev 2009;229:114-25.

84. Youngblood B, Oestreich KJ, Ha SJ, Duraiswamy J, Akondy RS, West EE, et al. Chronic virus infection enforces demethylation of the locus that encodes PD-1 in antigen-specific CD $8(+) \mathrm{T}$ cells. Immunity 2011;35:400-12.

85. Mackenzie KJ, Nowakowska DJ, Leech MD, McFarlane AJ, Wilson C, Fitch PM, et al. Effector and central memory T helper 2 cells respond differently to peptide immunotherapy. Proc Natl Acad Sci USA 2014;111:E784-93.

86. Raddassi K, Kent SC, Yang J, Bourcier K, Bradshaw EM, Seyfert-Margolis V, et al. Increased frequencies of myelin oligodendrocyte glycoprotein/MHC class II-binding CD4 cells in patients with multiple sclerosis. J Immunol 2011;187:1039-46.

87. Yang J, Chow IT, Sosinowski T, Torres-Chinn N, Greenbaum CJ, James EA, et al. Autoreactive T cells specific for insulin B: 11-23 recognize a low-affinity peptide register in human subjects with autoimmune diabetes. Proc Natl Acad Sci USA 2014; 111:14840-5.

88. Bacher P, Schink C, Teutschbein J, Kniemeyer O, Assenmacher M, Brakhage AA, et al. Antigen-reactive T cell enrichment for direct, high-resolution analysis of the human naive and memory Th cell repertoire. J Immunol 2013;190:3967-76.

89. Anderton SM. Post-translational modifications of self antigens: Implications for autoimmunity. Curr Opin Immunol 2004;16:753-8. 